Araștırma ve Geliștirme Dergisi

International Journal of

Engineering Research and

Development
UMAGD, (2021) 13(2), 704-710.

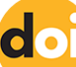

10.29137/umagd.913816

Cilt/Volume:13 Sayı/Issue:2 Haziran/June 2021

Araştırma Makalesi / Research Article

\title{
An Investigation of Production and Properties of RHA Reinforced Hybrid Composites by Vacuum Infiltration Method
}

\author{
Naci Arda Tanış ${ }^{1}$, , Onur Okur ${ }^{1}$ iD, ${\text { Erkan } \text { Yılmaz }^{2} \text { iD }, \text { Mustafa Türkmen }^{3} \text { iD, Azmah Hanim Binti Mohamed Ariff }}^{4}$ iD \\ , Temitope T. Dele-Afolabi ${ }^{4}$ Recep Çalın ${ }^{1}$ iD \\ ${ }^{1}$ Dept. of Metallurgical and Materials Engineering, Faculty of Engineering and Architecture, Kirikkale University, Kirikkale, 71450, TURKEY \\ ${ }^{2}$ Sima Aluminium, Kocaeli, 41420, TURKEY \\ ${ }^{3}$ Transportation Technologies Institute, Gebze Technical University, Kocaeli, 41380, TURKEY \\ ${ }^{4}$ Advance Engineering Materials and Composites Research Center, (AEMC), Faculty of Engineering, Universiti Putra Malaysia, 43400 UPM \\ Serdang, Selangor, MALAYSIA
}

Başvuru/Received: 29/03/2021

Kabul / Accepted: 08/06/2021

Çevrimiçi Basım / Published Online: 18/06/2021

Son Versiyon/Final Version: 18/06/2021

\begin{abstract}
The harmful effect of agricultural waste has been intensified over the last decade and impacts the environment every passing day. Rice husk waste is a major problem in Turkey and the far east countries. Due to the economic dependence of the mass cultivation and the production of rice, the disposal of the waste appears both time and money consuming. Alternative methods sought over the years and the implementation of the rice husk in the production of composites is seen as a promising method. RHA is a burning residue of rice husk and the implementation of RHA in the production of aluminum composites gained attention in recent years. In this study, aluminum composites having 5 wt. $\% \mathrm{Al}_{2} \mathrm{O}_{3}$ reinforcement and 5 wt. $\% \mathrm{Al}_{2} \mathrm{O}_{3} / 0.5,1.0$, and 1.5 wt. $\%$ RHA reinforcement were produced by vacuum infiltration process which is a cheap and cost-effective route. AA7075 alloy without any reinforcement was produced for comparison. Solution heat treatment at $480{ }^{\circ} \mathrm{C}$ for 2 hours was applied and then quenched following by aging heat treatment at $120^{\circ} \mathrm{C}$ for 8 hours. The microstructure, microhardness, and wear tests of all composites were investigated. Increasing RHA content up to $1 \mathrm{wt} . \%$ and aging heat treatment increased the hardness of composites. Wear coefficient decreased by increasing RHA content.
\end{abstract}

Key Words

"RHA, $\mathrm{Al}_{2} \mathrm{O}_{3}$, Vacuum infiltration, $\mathrm{AA}$ 7075, Aging heat treatment, Wear test" 


\section{Introduction}

The wide application of metal matrix composites (MMCs) in automotive, aviation, transport, and defense industries has provided many benefits in terms of their high mechanical strength, high wear resistance, good thermal stability, good corrosion resistance, and relatively low density (Zhang et al. 2013). Metal matrix composites generally consist of two or more constituents which favorably combine the overall characteristics of each constituent. As being one of the constituents, metal matrix is generally chosen among aluminum, titanium, magnesium, iron, and their alloys (Kaushik and Rao, 2016). While each matrix material ensures unique properties, aluminum and its alloys are by far the most preferred matrix materials since it is a good solution in weight reduction of vehicles along with providing attractive mechanical properties. As for the other constituents of metal matrix composites, many oxides and carbides such as $\mathrm{SiC}, \mathrm{B}_{4} \mathrm{C}, \mathrm{Al}_{2} \mathrm{O}_{3}, \mathrm{MgO}$, and $\mathrm{TiC}$ are used as reinforcement which bring interesting properties into metal matrix composites. $\mathrm{Al}_{2} \mathrm{O}_{3}$ reinforced aluminum composites find a wide range of applications in automotive industry such as brake discs, piston, cylinder shells, and steering shaft where high wear resistance is a critical requirement (Prasad and Ashtana, 2004). However, the high production cost of metal matrix composites should be taken into account in comparison with the conventional materials used in automotive industry.

Recently, more researchers have focused on aluminum matrix composites reinforced with agricultural waste due to the high cost of ceramic reinforcements (Prakash et al. 2017). The most used agricultural and industrial waste materials are volatile coal ash (FA), red mud, rice husk ash (RHA), bamboo fiber ash, and sugar cane ash (Shaikh et al. 2019). Among the many agricultural waste used as reinforcements, RHA is one of the most widely employed in the production of metal matrix composites. Every year, thousands of tons of rice waste generated due to the large-scale production of rice. Current rice production in the world is estimated to be over 700 million tons and rice husk constitutes around $20 \%$ of the weight of rice. RHA is the product of incineration of rice husk and the characteristics of the ash are mainly dependent on three parameters: (1) chemical composition of the rice husks, (2) burning time, and (3) burning temperature. Every $100 \mathrm{~kg}$ of husks burnt in a boiler yields around $25 \mathrm{~kg}$ of RHA. When considering the vast amount of rice husk waste and RHA as its incineration product, it seems plausible to use of RHA in the production of aluminum matrix composites due to the fact that it is attainable and cost-efficient (Prasad and Krishna, 2012).

The boost of advancement in technology is unprecedented and outpaces the modern-day technology provided by suppliers. This pushes the limits of engineering and science and brings about the birth of a new class of composites named as hybrid composites. Hybrid composites consist of two or more reinforcements and each reinforcement gives the distinctive characteristic to composite. Even the most demanding properties can be accomplished by choosing the optimum combination between reinforcement materials. Therefore, as for the right combination, not only type and number of reinforcements but also volume fraction and morphology of reinforcements are prerequisites in achieving the best combination. Along with materials selection, the selection of the production method is a vital step for low-cost production. Many methods such as casting, powder metallurgy, in-situ processes, and infiltration are used to produce aluminum matrix composites. The infiltration method stands out as one of the most effective method among other production methods, the method includes non-pressure, pressure, and vacuum infiltration methods (Çalın and Çıtak, 2007). The infiltration technique is a relatively simple and a cost-efficient process that involves filling the pores between the preformed reinforcements as molten metal proceeds through the mold. Therefore, molten metal fills the pores of the preform and allow matrix to constitute composite (Surappa, 2003). In vacuum infiltration technique, a vacuum pipe which is connected to vacuum pump is attached to mold which is made of a glass or a stainless-steel tube. When mold dips into molten metal, a low pressure via vacuum line which is attached to the top of the mold is obtained by turning on the vacuum pump and, thus, this pressure enables the proceeding of metal into the mold (Duran et al. 2018).

Researches on the synthetic reinforcements such as $\mathrm{SiC}, \mathrm{B}_{4} \mathrm{C}, \mathrm{Al}_{2} \mathrm{O}_{3}, \mathrm{MgO}$, and $\mathrm{TiC}$ have been intensively carried out for many decades Likewise, there are plenty number of studies dedicated to hybrid synthetic reinforced composites. However, studies focused on the hybrid composites consist of synthetic and agro-waste reinforced composites are few. Overview of some of the recent studies focused on synthetic and agro-waste hybrid reinforced composites presented below. Alanem et al. produced $\mathrm{RHA}$ and $\mathrm{Al}_{2} \mathrm{O}_{3}$ reinforced hybrid aluminum composites by two-step stir casting method. It was observed that there was a slight decrease in hardness and tensile strength of the hybrid as compared to the monolithic reinforced $\mathrm{Al}_{2} \mathrm{O}_{3}$ composites. Promising results were obtained with the composites containing $2 \mathrm{wt} . \%$ RHA which exhibited better strength, elongation and fracture toughness as compared to the monolithic and hybrid reinforced composites. Prasad et al. used double stir casting method to produce RHA and SiC hybrid reinforced composites and they reported that while elongation decreases with the increase in reinforcement, tensile strength and yield strength increase with an increase in the percent weight fraction of the reinforcement particles. They concluded that hybrid reinforced aluminum composites with up to $8 \mathrm{wt} . \%$ rice hush ash and $\mathrm{SiC}$ particles could be produced by using double stir casting method.

As can be inferred from the overview, the studies carried out by implementing different production methods are scarce. Therefore, this study focused on the production of synthetic and agro-waste hybrid reinforced aluminum composites by vacuum infiltration method and the hardness and wear properties of the composites were investigated.

\section{Materials and Methods}

In this study, AA7075 alloy was chosen as matrix. $\mathrm{Al}_{2} \mathrm{O}_{3}$ and $\mathrm{RHA}$ were chosen as reinforcement materials. The chemical composition of the aluminum alloy and RHA was determined and presented in Table 1 and Table 2, respectively. 
Table 1. Elemental composition of AA7075

\begin{tabular}{cc}
\hline Element & wt.\% \\
\hline $\mathrm{Al}$ & 89.9 \\
$\mathrm{Zn}$ & 5 \\
$\mathrm{Mg}$ & 2.6 \\
$\mathrm{Cu}$ & 1.6 \\
$\mathrm{Cr}$ & 2.6 \\
\hline
\end{tabular}

Table 2. Elemental composition of the RHA

\begin{tabular}{cc}
\hline Element & wt.\% \\
\hline $\mathrm{C}$ & 6.78 \\
$\mathrm{O}$ & 56.40 \\
$\mathrm{Si}$ & 35.74 \\
$\mathrm{Mg}$ & 0.43 \\
$\mathrm{Ca}$ & 0.66 \\
\hline
\end{tabular}

The preforms consisting of 5:0, 5:0.5, 5:1.0, and 5:1.5 wt.\% $\mathrm{Al}_{2} \mathrm{O}_{3}$ and $\mathrm{RHA}$, respectively, were mixed to produce aluminum 7075 matrix composite materials. The schematic representation of the steel tube used in the vacuum infiltration method is given in Figure 1. The inner diameter of the steel tube is $10 \mathrm{~mm}$, the wall thickness is $1 \mathrm{~mm}$ and the length of the tube is $300 \mathrm{~mm}$. After the stainless-steel filter was placed at the bottom part of the tube, the preform was placed into the tube. Another stainless-steel filter was placed on top of the preform, silica sand grains are placed on top of that filter to prevent the molten metal from proceeding the vacuum line. Lastly, stainless-steel filter was placed to the top of the tube to keep silica grains from getting through the vacuum line. The vacuum pump was started up and infiltration tube was dipped into molten metal. The infiltration tube was pulled out of the molten metal after 3 minutes, and was left to cool down to room temperature. Finally, the tubes were machined to remove the steel tube mold and get the composite materials.
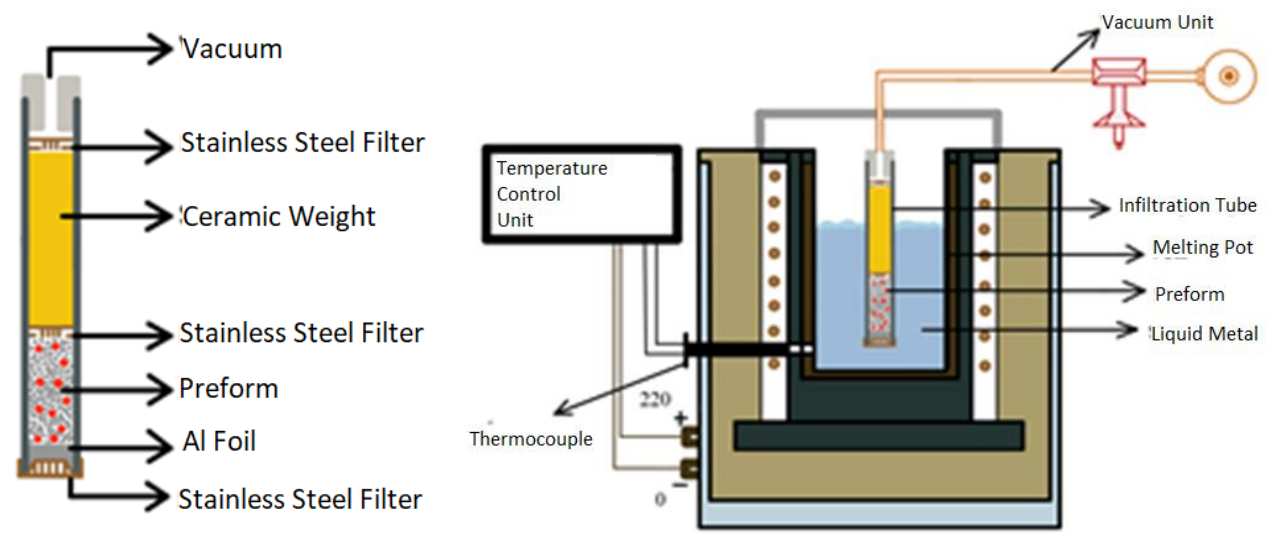

Figure 1. Schematic figures of a) infiltration tube and b) vacuum infiltration setup.

Some of the composites produced by vacuum infiltration method was left as-cast and others were further taken into the furnace for solid solution heat treatment and the heat treatment temperature was $480{ }^{\circ} \mathrm{C}$ and duration was 2 hours. After 2 hours, the composites were quenched and taken to another furnace for T6 aging heat treatment. Aging heat treatment was applied at $120^{\circ} \mathrm{C}$ for 8 hours. The schematic figure of T6 heat treatment is given in Figure 2. After aging heat treatment, microstructure analysis, microhardness values, and wear tests on the pin-on-disc device were performed and microstructure images were taken by using scanning electron microscope. 


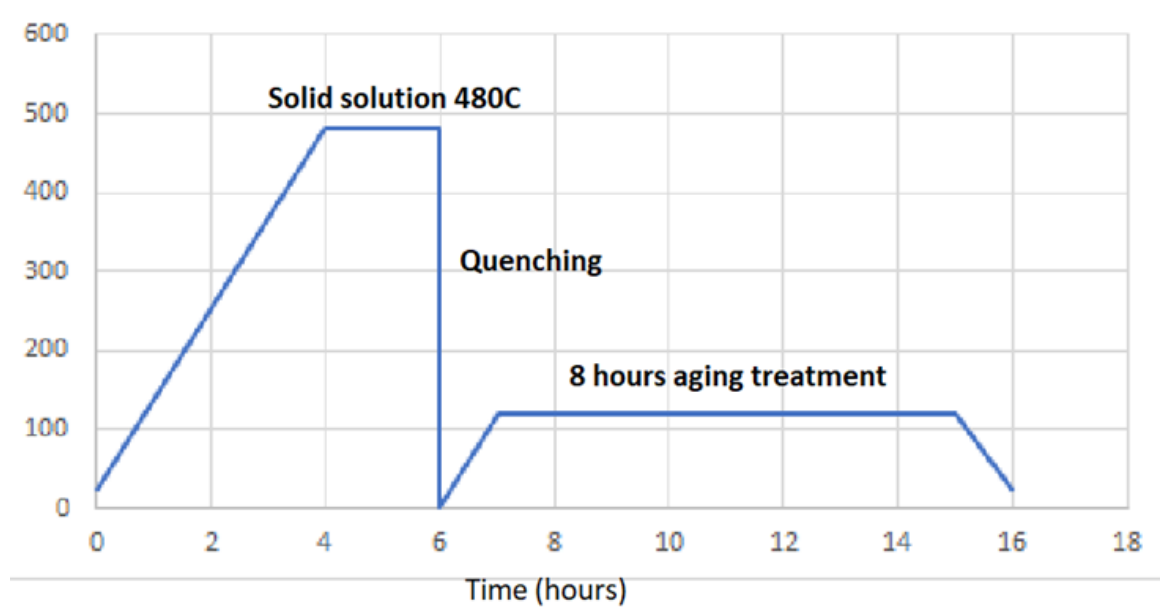

Figure 2. Schematic image of the heat treatment applied to the samples

\section{Result and Discussion}

Figure 3.a shows the microstructure image of the RHA reinforcement particles. As can be seen from the figure, RHA particles have a long and porous structure. In Figure 3.b, the microstructure image of the sample containing $1 \mathrm{wt} . \%$ RHA. As can be understood from the microstructural images, the particle fell off the surface during the sanding and polishing processes, but its replica remained on the surface. In this way, it has made it possible to examine the distribution of particles on the surface.
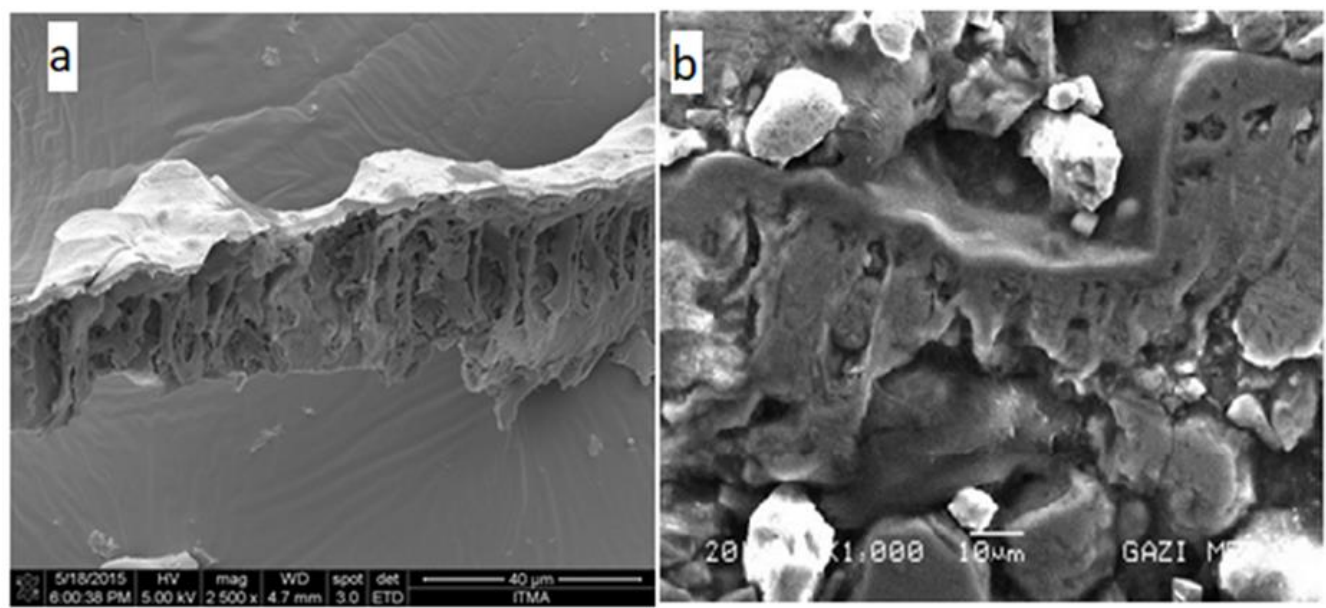

Figure 3. SEM image of a) RHA particle and b) replica of RHA on matrix
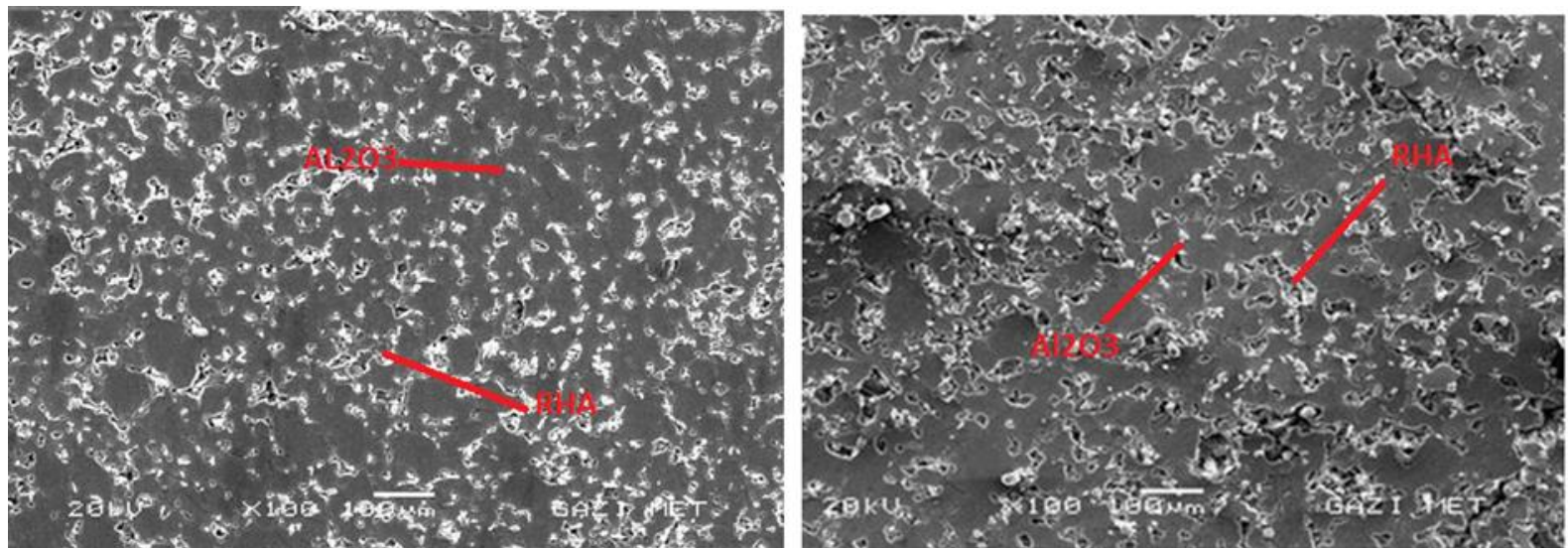

Figure 4.a) SEM image of the sample containing 0.5\% RHA and b) SEM image of the sample containing 1\% RHA

SEM images of aged for 8 hours 5 wt. $\% \mathrm{Al}_{2} \mathrm{O}_{3} / 0.5$ wt. $\%$ RHA/AA7075 matrix composite and 5 wt. $\% \mathrm{Al}_{2} \mathrm{O}_{3} / 1$ wt. $\%$ RHA/AA7075 are shown in Figures 4.a and b, respectively. It can be seen that $\mathrm{Al}_{2} \mathrm{O}_{3}$ reinforcement were homogeneously distributed in the samples. It is 
noteworthy to indicate that long and narrow pores increased as RHA content increases shown in Figure 4.a and 4.b. This is due to the poor wettability of RHA particles by melting metal. Additionally, the analyze carried out by SEM revealed that there are white/gray regions around the pores formed by the pulled-off RHA particles. EDS analysis taken from these regions showed that mainly Si and C elements diffused into the matrix.

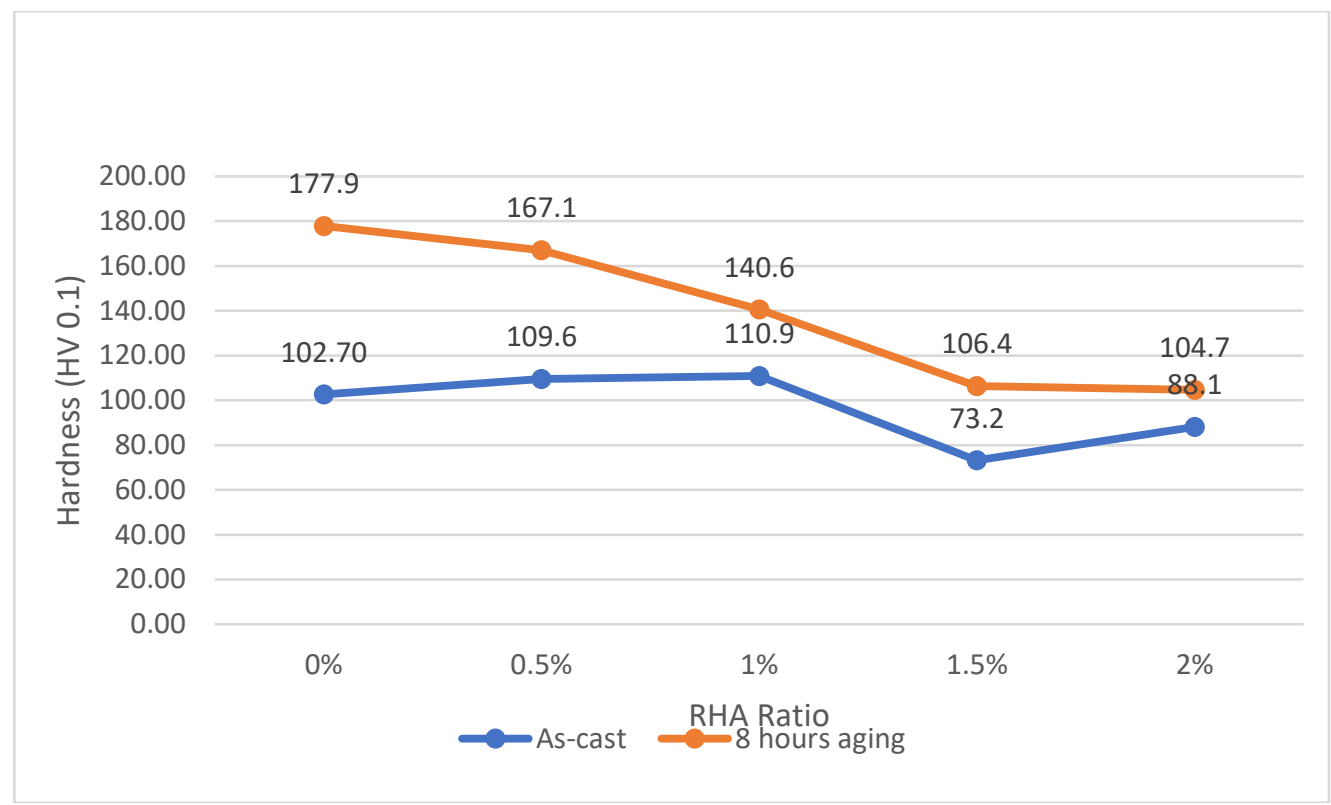

Figure.5 Hardness of samples that were non-heat treated and heat-treated for 8 hours

Microhardness tests were carried out with non-heat treated samples and T6 heat treated for 8 hours at a loading of $200 \mathrm{~g}$, as shown in Figure 5, it is observed that the hardness of all samples increased as a result of the 8 hours aging process. While the highest hardness increase was observed in the sample with $0 \mathrm{wt} . \% \mathrm{RHA} / 5 \mathrm{wt} . \% \mathrm{Al}_{2} \mathrm{O}_{3}$ reinforced aluminum matrix which increased $102.7 \mathrm{HV}$ in ascast sample to $177.9 \mathrm{HV}$ in 8 hours aging heat treated sample. It is determined that the hardness difference between the non-heattreated and heat-treated samples decreased as the RHA reinforcement ratio increased. Among the non-heat treated samples, the highest hardness value was determined as $110.9 \mathrm{HV}$ in the composite containing $5 \mathrm{wt} . \% \mathrm{Al}_{2} \mathrm{O}_{3} / 1$ wt.\% RHA, and the lowest hardness value was 73.2 for the sample containing $5 \mathrm{wt} . \% \mathrm{Al}_{2} \mathrm{O}_{3} / 1.5 \mathrm{wt} . \%$ RHA reinforcement. It is thought that the reason of the decrease in hardness might be the aggregation of the reinforcement that were non-homogeneously distributed and caused the pores. SEM images confirm this interpretation. The highest hardness after heat treatment is observed in the sample without RHA reinforcement and the hardness decreased with the increasing weight percentage of RHA reinforcement. Çalın (2019) obtained similar results in his study on aluminum matrix RHA reinforced hybrid composites in 2019.

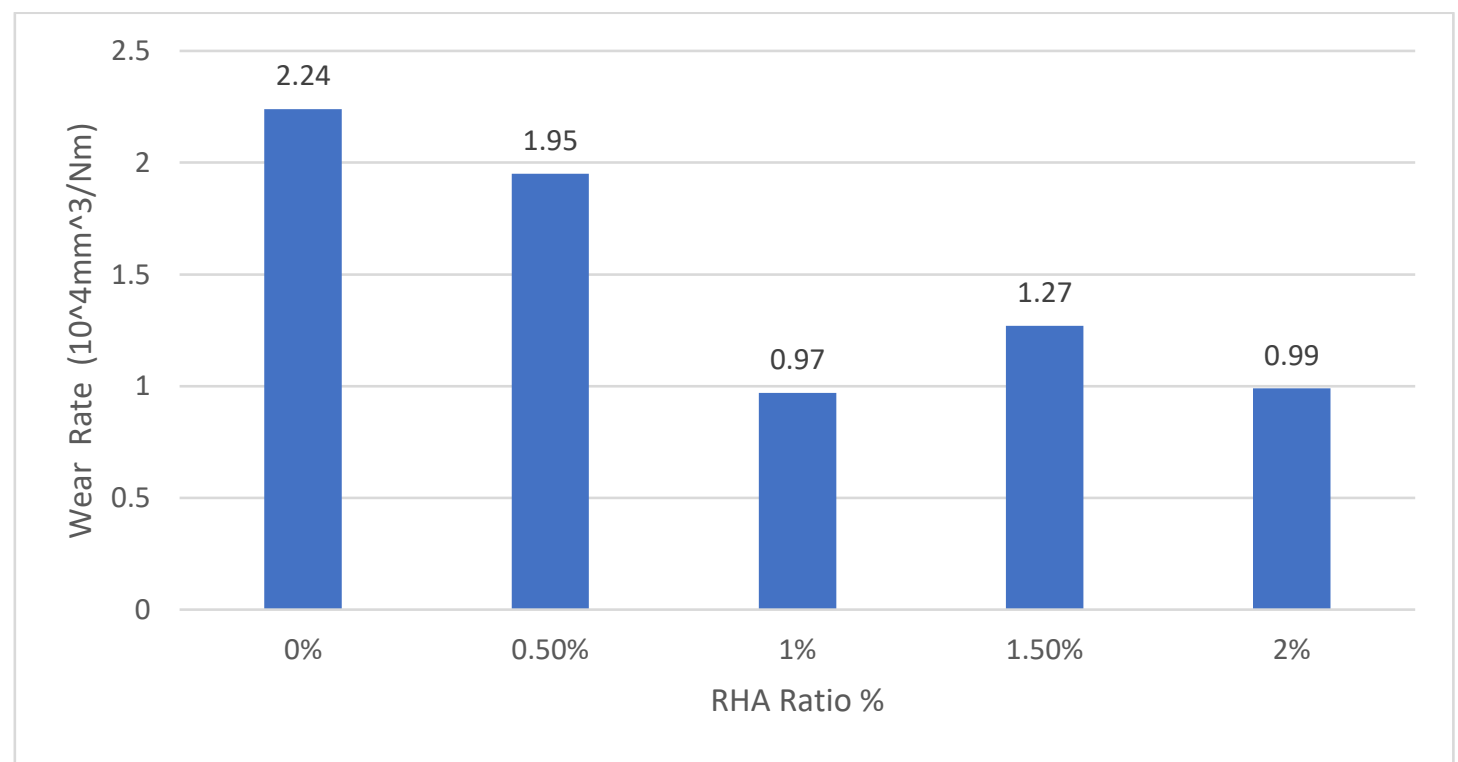

Figure 6. Wear rate of composites with 5 wt. $\% \mathrm{Al}_{2} \mathrm{O}_{3}$ and $0.5,1,1.5,2$ wt.\% RHA aged for 8 hours and $\mathrm{AA} 7075$ matrix composites. 
Wear rates of samples were calculated by weight loss and aged for 8 hours are given in Figure 6. When the rates were taken into consideration, the lowest wear rate was detected in the sample containing 5 wt. $\% \mathrm{Al}_{2} \mathrm{O}_{3} / 1$ wt. $\%$ RHA, while the sample without RHA reinforcement had the highest rate of wear. Considering the hardness of composites in Figure 5, it is expected that the wear rate will be less because the hardness is the highest in the samples without RHA, but the hardness values were taken directly from the matrix, not from the grain. During the pin-on disc test, wear also occurred on the surface of RHA particles and it was seen from Figure 6 that the RHA particles reduced the wear rate. While the wear rate decreased in proportion to increase in RHA content up 1 wt. \%, the wear rate increased slightly in the composite containing $1.5 \%$ wt. RHA. Özyürek et al. (2016) found similar results which higher wear rates in their pin-on disc test on non-aged specimens at the same reinforcement rates. It was observed that the wear rate decreased with 8 hours aging process.

\section{Conclusions}

- $\mathrm{Al}_{2} \mathrm{O}_{3}$ ceramic reinforcement is homogeneously distributed throughout the samples while some agglomeration detected in the composites having higher RHA content.

- Regarding the hardness of $\mathrm{Al}_{2} \mathrm{O}_{3}$ and $\mathrm{RHA}$ reinforced hybrid composites with AA7075 matrix, while the highest hardness was observed in the non-heat treated sample containing 1\% RHA. As RHA content increases, the hardness decreased in all aging heat treated samples.

- As can be understood from the pin-on disc tests, it was determined that the 8-hour aging heat treatment reduced the wear rate and the lowest wear rate was attained in the sample containing $1 \%$ RHA reinforcement.

\section{Acknowledgements}

This study was supported by the Research Management Center, Universiti Putra Malaysia (UPM- Grant Putra; UPM/7002/1/GPBI/2017/9553600) and the Department of Metallurgy and Materials Engineering, Kirikkale University, Turkey (project number of BAP2017/81 and 2016/44).

\section{Refereences}

Bhansali K.J., Mehrabian R. (1982). Abrasive Wear of Aluminum-Matrix Composites, J. Met., 3 1. 30-34.

Calin R., Citak R. (2007). Effect of powder size on infiltration height in producing $\mathrm{MgO}$ reinforced $\mathrm{Al}$ matrix composite by vacuum infiltration method; in Materials science forum, vol. 534: Trans Tech Publ, pp. 797-800.

Duran O., Okur O., Tanis N.A., Calin R., Azmah Hanim M.A., Dele-Afolabi T.T. (2018). Investigation on the Properties of AgroWaste Reinforced Aluminum Matrix Composites. Presented in Symposium and Workshop on Materials and Characterization, 24-25th July 2018.

Kaushik NC, Rao R.N. (2016). Effect of grit size on two body abrasive wear of Al 6082 hybrid composites produced by stir casting method, Tribology International, Volume 102, Pages 52-60, ISSN 0301-679X,

Prakash Kumarasamy S., Vijayananth K., Thankachan T., Pudhupalayam M.G. (2017). Investigations on mechanical and machinability behavior of aluminum/flyash cenosphere/Gr hybrid composites processed throug compocasting, J. Appl. Res. Technol. 15 430-441.

Prasad D.S., Krishna A.R. (2012). Tribological Properties of A356.2/RHA Composites, Journal of Materials Science \& Technology, Volume 28, Issue 4, Pages 367-372, ISSN 1005-0302.

Prasad S.V., Asthana R. (2004). Aluminium metal-matrix composites for automotive applications: tribology considerations Tribol Lett, 17 (3), pp. 445-453

Shaikh M.B.N., Sajjad A., Tariq A.,Waseem A., Shaikh M.A.N., Ali M. (2019). Microstructural, mechanical and tribological behaviour of powder metallurgy processed SiC and RHA reinforced Al-based composites, Surfaces and Interfaces, Volume 15, Pages 166-179, ISSN 2468-0230,

Surappa M.K. (2003). Aluminium matrix composites: Challenges and opportunities; Sadhana, journal article vol. 28, no. 1, pp. 319 334.

Tanis N.A, Okur O., Duran O., Dele-Afolabi T.T., Azmah Hanim M.A., Calin R. (2019) An Investigation on the Properties of RHA and A12O3 Reinforced Hybrid Composites Case Study On Material Engıneerıng And Applied Sciences: ISBN 978-983-2408-68-0 p. 57-67, UPM Malaysia. 
Yildirim, M., Özyürek, D., Gürü, M. (2016). The Effects of Precipitate Size on the Hardness and Wear Behaviors of Aged 7075 Aluminum Alloys Produced by Powder Metallurgy Route. Arab J Sci Eng 41, 4273-4281 https://doi.org/10.1007/s13369-016-2078-6

Zhang J, Jung-Moo L, Young-Hee C, Su-Hyeon K,Yu H. (2013) Fabrication of aluminum matrix composites by quick spontaneous infiltration process through combustion reaction of $\mathrm{Al}-\mathrm{Ti}-\mathrm{B} 4 \mathrm{C}-\mathrm{CuO}$ powder mixtures in molten aluminum, Scripta Materialia, Volume 69, Issue 1, Pages 45-48, ISSN 1359-6462, 